\title{
Genetic analysis of lung function in inbred mice suggests vitamin $D$ receptor as a candidate gene
}

\author{
Annerose Berndt • H. S. Savage • T. M. Stearns • \\ B. Paigen
}

Received: 21 March 2011/Accepted: 4 August 2011/Published online: 19 August 2011

(C) The Author(s) 2011. This article is published with open access at Springerlink.com

\begin{abstract}
Vitamin D receptor (VDR) polymorphisms are associated with an increased asthma incidence in human populations; however, observations in $V d r$ knockout mice are unclear. The aim of our study was to determine the influence of the genetic variation in $V d r$ among inbred strains on lung resistance (i.e., dynamic and airway resistance). In an intercross between the strains C57BL/6J (B6) and $\mathrm{KK} / \mathrm{HIJ}(\mathrm{KK})$, we identified that a significant QTL for dynamic resistance on Chr X was interacting with a QTL on Chr 15. The Chr 15 QTL peak was located in close proximity to the $V d r$ locus. We further examined if phenotypes of several inbred strains with varying $V d r$ genotypes differed. Strains with a B6-like genotype on the $V d r$ locus had significantly lower airway resistance than strains with a KK-like genotype. $V d r$ knockout mice were examined for dynamic resistance and showed significantly higher resistance than mice with one (i.e., heterozygous) or both copies (i.e., wild-type) of the $V d r$. In comparison to $\mathrm{B} 6$, the strain $\mathrm{A} / \mathrm{J}$ is more resistant but carries the same genotype at the $V d r$ locus. Dietary vitamin D manipulation
\end{abstract}

Communicated by S. Hohmann.

Electronic supplementary material The online version of this article (doi:10.1007/s00438-011-0642-z) contains supplementary material, which is available to authorized users.

A. Berndt · H. S. Savage - T. M. Stearns · B. Paigen

The Jackson Laboratory, Bar Harbor, ME, USA

Present Address:

A. Berndt $(\square)$

University of Pittsburgh, Pittsburgh, PA, USA

e-mail: anb128@pitt.edu in the strain $\mathrm{A} / \mathrm{J}$ did not rescue the high airway resistance phenotype. Finally, we observed that serum vitamin D does not correlate significantly with lung resistance parameters in a survey of 18 strains. Conclusively, $V d r$ contributes to the phenotypic variation of lung resistance in inbred mice but other molecules in the $V d r$ pathway and extended network [i.e., Chr X gene(s)] may contribute as well.

Keywords Airway responsiveness - Vitamin D receptor . Vdr - QTL mapping · Asthma · Genetics · Dietary vitamin $\mathrm{D}$ manipulation $\cdot \mathrm{KK} / \mathrm{HIJ}$

\section{Introduction}

Chronic lung diseases such as asthma are characterized by inflammatory and obstructive processes within the lungs (Stevenson and Birrell 2011), which can be detected by changes of lung resistance (i.e., dynamic and airway resistance). The disease pathogenesis is complex and influenced by both genetic and environmental factors. Identifying the primary genetic factors that influence lung function changes will enhance our understanding about the risk factors and, ultimately, help to determine novel molecular pathways and targets for therapeutic interventions. However, environmental factors vary often among and within human study populations; thus, making it difficult to compare results between studies and to isolate disease-causing genetic variations. Mouse models of lung diseases can help to accelerate the identification of genetic determinants because their environment can be controlled and because of the availability of a broad range of genetic resources for many inbred strains (Peters et al. 2007).

Genetic mouse crosses for finding quantitative trait loci (QTLs) have been used to localize and identify genes 
underlying complex traits of human disorders, e.g., cardiovascular diseases, diabetes, and kidney diseases (Mu et al. 1999; Sheehan et al. 2007; Su et al. 2009). Similar approaches have been applied to identify novel genetic determinants for airway responsiveness (Stylianou et al. 2007). Compared to those earlier studies that aimed to identify novel genetic variations QTL crosses can also be used as a tool to verify a gene of interest. Crossing two inbred strains has the power to detect segregating alleles that have moderate affects (5-10\% of total variance). Therefore, a QTL cross for which parental strains are selected due to differing alleles or haplotypes in a gene of interest can determine if the gene has at least a moderate affect on the phenotype.

The highest incidence of asthma is found in developed countries where people spend more time indoors and are less exposed to sunlight, conditions that may lead to vitamin D deficiency (Masoli et al. 2004). Epidemiological studies have demonstrated that vitamin D supplements during pregnancy lead to a lower incidence of asthma in children and that vitamin D deficiency is associated with increased asthma symptoms (Devereux et al. 2007; Saadi et al. 2009b). Moreover, VDR polymorphisms have been linked to increased asthma incidence in several human populations (Raby et al. 2004; Saadi et al. 2009a). However, literature on the role of $V d r$ in airway responsiveness in mice is controversial because previous investigators showed that mice deficient in $V d r$ have decreased asthmalike symptoms (Wittke et al. 2004).

Recently, our laboratory reported that mice of different inbred strains show wide variations in lung function parameters when exposed to increasing doses of aerosolized methacholine (Leme et al. 2010; Berndt et al. 2011). In a survey of 36 mouse strains, airway responsiveness was highest in strain KK/HIJ (KK) and lowest in strain C57BL/ $6 \mathrm{~J}$ (B6). Interestingly, genotype alleles of these two strains differ in exons of the $V d r$ gene.

In this study we aimed to determine the effect of the $V d r$ genotype on dynamic and airway resistance in a QTL cross between the strains KK and B6. We further hypothesized that strains with different $V d r$ genotypes would differ in lung resistance phenotypes and $V d r$ knockout mice have higher lung resistance compared to wild-type mice. We tested if the lung resistance phenotypes of strain A/J, which has the same $V d r$ genotype as B6 but shows elevated airway responsiveness, can be rescued by dietary vitamin D regimens. Due to the significant difference in airway responsiveness between $\mathrm{KK}$ and $\mathrm{B} 6$ we examined if 25-hydroxyvitamin D3 [25(OH)D3], the major circulating vitamin D3 metabolite, differed between the parental strains. Finally, we proposed that strains with varying airway resistance proportionally differ in their serum vitamin D concentrations.

\section{Experimental procedures}

Mice

All mice were obtained from The Jackson Laboratory (Bar Harbor, ME). KK and B6 mice were mated to produce $(\mathrm{KK} \times \mathrm{B} 6) \mathrm{F} 1$ and $(\mathrm{B} 6 \times \mathrm{KK}) \mathrm{F} 1$ reciprocal progeny. The $(\mathrm{KK} \times \mathrm{B} 6) \mathrm{F} 1$ progeny were intercrossed to produce an $\mathrm{F} 2$ population of 147 females and 132 males. The animal room

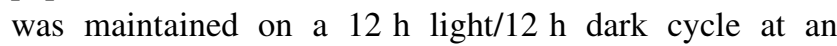
ambient temperature of $21-23^{\circ} \mathrm{C}$. Mice of the same sex (maximum 5 per pen) were housed in duplex polycarbonate cages $(31 \times 31 \times 214 \mathrm{~cm})$ in pressurized individually ventilated mouse cages (Thoren Caging System, Hazelton, PA) with a high-efficiency particulate air-filtered supply and exhaust. Mice were allowed ad libitum access to acidified water ( $\mathrm{pH}$ 2.8-3.2) and pellets containing $6 \%$ fat (LabDiet 5K52, PMI Nutritional International, Bentwood, $\mathrm{MO}$ ). The mouse colonies were regularly monitored (four times/year) and found to be free of 17 viruses [ectromelia virus, GDVII (Theiler's) virus, Hantaan virus, K virus, lactic dehydrogenase elevating virus, lymphocytic choriomeningitis, mouse adenovirus, mouse cytomegalovirus, mouse hepatitis virus, mouse minute virus, mouse norovirus, mouse parvovirus, mouse thymic virus, pneumonia virus of mice, polyoma virus, reovirus 3 , and rotavirus], 17 bacterial species (including Helicobacter spp., Pasteurella pneumotropica, and two Mycoplasma spp.), external and internal parasites, and the microsporidium Encephalitozoon cuniculi. Animal protocols were reviewed and approved by the Animal Care and Use Committee at The Jackson Laboratory. Mouse handling and care were followed according to the Public Health Service animal welfare policies.

Detection of lung function parameters with forced oscillation technique

Lung functions were measured in 11-week-old mice by invasive forced oscillation technique. Briefly, mice were anesthetized with ketamine and xylazine $(50-100 \mathrm{mg} / \mathrm{kg}$ of ketamine and $5-10 \mathrm{mg} / \mathrm{kg}$ of xylazine injected i.p., Phoenix Scientific, Inc.), a tracheostomy was performed, and mice were attached to a computer-controlled piston ventilator (flexiVent system, SCIREQ, Montreal, Quebec). Each mouse was ventilated at tidal volume $\left(V_{\mathrm{t}}\right)$ of $10 \mathrm{ml} / \mathrm{kg}$ at 150 breaths/min with $0 \mathrm{cmH}_{2} \mathrm{O}$ positive end-expiratory pressure (i.e., baseline ventilation). Following 5 min of stabilization and administration of pancuronium bromide (0.8 mg/kg i.p., Sicor Pharmaceutical, Inc.), a deep lung inflation was applied to ensure uniform lung recruitment and to normalize to the same volume history for each mouse. This deep inflation procedure consisted of a 
constant airflow with a pressure limited to $40 \mathrm{cmH}_{2} \mathrm{O}$ over $3 \mathrm{~s}$ followed by a passive exhalation. Saline and methacholine aerosol challenge measurements (1, 3, 10, 20, and $30 \mathrm{mg} / \mathrm{ml}$ methacholine; $100 \mu \mathrm{l}$ solution of each dose used for each animal) were obtained by channeling the inspiratory flow from the ventilator through an ultrasonic nebulizer (Aeroneb ${ }^{\circledR}$ Lab Nebulizer System by Aerogen Ltd., Galway, Ireland). During aerosol challenge the piston delivered a $V_{\mathrm{t}}$ of $40 \mathrm{ml} / \mathrm{kg}$ at $30 \mathrm{breaths} / \mathrm{min}$. After each aerosol challenge, the piston returned to baseline ventilation and aerosol challenge measurements were taken, after which a deep inflation was applied to re-open the lungs for the next aerosol challenge.

Lung function measurements were obtained by two techniques. First we applied a single compartment model that measures dynamic resistance (i.e., $R$ ). Second, a constant phase model of the viscoelastic lung was fitted to derive central airway resistance (i.e., Newtonian resistance, $R_{\mathrm{n}}$ ). We collected data from 12 cycles (12 single compartment measurements and 12 constant phase model measurements) after each aerosol challenge (e.g., saline and methacholine) to detect the peak of each lung function parameter. The three data points surrounding the highest value were used to calculate an average response at each dose.

\section{Analysis of lung function phenotypes}

For the lung function phenotypes, we determined the strength of increase (i.e., slope) caused by consecutive doses of methacholine exposure. First we calculated the average value for the three highest responses at each dose for each mouse (i.e., individual value). The individual values were then plotted against log-transformed methacholine concentrations and a linear curve was fitted. The increase of this curve is equivalent to the slope, which was used as phenotypic parameter in our investigations.

\section{DNA isolation and genotyping}

After lung function measurements, mice were killed and tail tips were collected for DNA isolation and genotyping. DNA was isolated using a genomic DNA purification kit (Kit-D-7000A, Gentra Systems, Minneapolis, MN). DNA samples were genotyped on an Illumina genotyping platform as part of the Mutation Mapping and Developmental Analysis Project at Brigham and Women's Hospital (Harvard Medical School, Boston, MA). A total of 379 single nucleotide polymorphism (SNP) markers were polymorphic between KK and B6. For mapping purposes, the million base pair $(\mathrm{Mb})$ as well as the centimorgan (cM) positions of each SNP were derived from the Mouse Map Converter tool provided by The Center for Genome Dynamics at The Jackson Laboratory (http://cgd.jax.org/ mousemapconverter/), which utilizes the National Center for Biotechnology Information (NCBI) mouse genome build 37 and a corrected mouse map (Cox et al. 2009).

Quantitative trait locus (QTL) analysis

All QTL analyses were performed with the R/qtl software package (v. 1.18-7 available at http://www.rqtl.org/). To characterize QTLs we tested for single main-effect and interacting QTLs. We detected single main-effect loci for phenotypic differences among the F2 progeny. For this model we applied a regression analysis for each single marker using a one-way ANOVA $F$ statistic. 1,000 permutation tests were performed to determine the thresholds for significance. We used sex as a covariate in the following two models: (1) as additive covariate to account for overall differences between sexes, and (2) as interactive covariate to test the strength of interaction between sex and the potential QTL. QTLs that reached or exceeded the $95 \%$ genome-wide adjusted threshold (assessed by the 1,000 permutation tests for each phenotype) were termed significant. QTLs that reached or exceeded the 37\% threshold but did not reach the $95 \%$ genome-wide adjusted threshold were termed suggestive. To determine whether a QTL was sex-specific, those QTL that were significant in the main scan using the sex additive model were examined in the sex interactive model; if the LOD score difference between the two models was greater than $2,(\Delta \mathrm{LOD}>2$ based on the Chi-square distribution), the sex-by-QTL interaction was considered to be significant (Solberg et al. 2004).

We then searched for interacting loci using a two-way ANOVA $F$ statistic to test the hypothesis that the effect of loci pairs on the phenotype is significant (overall effect). To differentiate between the possibilities that the effect of two loci together on the phenotype is either due to an additive effect or due to an interactive effect, we computed another two-way ANOVA $F$ statistic to compare these two effects. If both, the overall and the interactive effect were significant (LOD $>10$ and $\mathrm{LOD}>4$, respectively), we concluded that the phenotype was affected by the interaction of the two loci. As with main-effect loci, we used sex as either an additive or interactive covariate. The difference between the two models was our test for sex-specific differences of the interacting loci.

Because the number of degrees of freedom for the linkage test may be different for the $\mathrm{X}$ chromosome than for autosomes, $\mathrm{X}$ chromosome-specific significance thresholds were calculated for each model scan (Solberg et al. 2004). 
Vitamin D receptor $(V d r)$ SNP influence on airway resistance

We examined the genotypes of $V d r$ among the 36 strains from our previous survey for airway responsiveness (Leme et al. 2010) using the SNP wizard from the Mouse Phenome Database (www.phenome.jax.org). We grouped the strains according to their genotype differences [known to cause a change in the amino acid (non-synonymous SNPs, Cn SNPs)] into a KK-like and B6-like group. Groups were compared for airway resistance. We analyzed female and male mice separately and combined. Strains with imputed genotypes at Cn SNPs of interest were excluded from the analysis.

Airway responsiveness in $V d r$ deficient mice

We obtained mice heterozygous for $V d r$ deficiency (stock 006133; B6.129S4-Vdr ${ }^{\mathrm{tm} 1 \mathrm{Mbd}} / \mathrm{J}$ ) from The Jackson Laboratory. These $V d r$ knockout mice have been backcrossed to B6 for eight generations, so the mutation is congenic on a B6 background. Mice are maintained as heterozygotes. The heterozygotes were mated to obtain progeny deficient in both copies ( $V d r$-KO) or one copy ( $V d r$-HET) of the $V d r$ and wild-type mice ( $V d r$-WT $=\mathrm{B} 6)$. We tested 11-weekold $V d r$-KO ( $n=9$ for females, $n=7$ for males), $V d r$ HET ( $n=10$ for females, $n=11$ for males), and $V d r$-WT ( $n=10$ for females and $n=10$ for males) for increase in lung resistance in response to consecutive doses of methacholine inhalation.

\section{Dietary vitamin D manipulation}

Male mice from the strain $\mathrm{A} / \mathrm{J}$ were obtained at 4 weeks of age. 18 mice were divided into three groups of six mice and each group was fed identical diets (Harlan Laboratories, South Easton, MA) except for their contents in vitamin D: (1) 4,500 IU of vitamin $\mathrm{D} / \mathrm{kg}$ of diet (i.e., vitamin D standard diet); (2) 25,000 IU of vitamin D/kg of diet (i.e., vitamin $\mathrm{D}$ enriched diet); and (3) vitamin $\mathrm{D}$ depleted diet (i.e., vitamin $\mathrm{D}$ deficient diet). At 11 weeks of age blood was collected for serum vitamin D analysis and lung function analyses were performed. All mice were maintained under UV light-controlled conditions to avoid cutaneous vitamin D production.

Vitamin D detection in serum samples

At 11 weeks of age blood of mice was drawn and serum was prepared. Serum aliquots were sent to Heartland Assays, Inc. (Iowa State University Research Park, Ames, IA), for measurement of $25(\mathrm{OH})$ vitamin D3 $(25(\mathrm{OH}) \mathrm{D})$. The $25(\mathrm{OH}) \mathrm{D}$ detection assay consisted of a multi-step procedure. The first procedure involved a rapid extraction of $25(\mathrm{OH}) \mathrm{D}$ and other hydroxylated metabolites from serum with acetonitrile. Following extraction, the treated sample was then assayed using an equilibrium radioimmunoassay (RIA) procedure. The RIA method is based on an antibody that is co-specific for $25(\mathrm{OH}) \mathrm{D} 2$ and $25(\mathrm{OH}) \mathrm{D} 3$. The sample, antibody, and tracer were incubated for $120 \mathrm{~min}$ at $20-25^{\circ} \mathrm{C}$. Phase separation was accomplished after a $20 \mathrm{~min}$ incubation at $20-25^{\circ} \mathrm{C}$ with a second antibody-precipitating complex. An addition buffer was added after this incubation prior to centrifugation to aid in reducing non-specific binding. 25(OH)D-equivalent values were calculated directly by the $\gamma$-radiation counting system with use of a smooth-spline method. The results were expressed in terms of $25(\mathrm{OH}) \mathrm{D}$ equivalents. To monitor assay performance each assay included one in-house control sample. The control was treated as unknown specimen and multiple determinations were made. Assay variation was determined and acceptable performance limits were defined as $\leq 15 \mathrm{CV}$.

Statistical analyses

Data are presented as mean \pm SEM. One-way ANOVA was performed to test for significant differences (1) between groups and sexes (F2 animals); (2) $V d r$-KO, $V d r$-HET, and $V d r$-WT; and (3) between diet groups. Student's $t$ test was used to test for differences between the groups. Pearson's correlation was used to examine the associations among serum vitamin $\mathrm{D}$ and airway resistance. Statistical significance was assigned at $P<0.05$. All statistical analyses were performed using JMP statistical analysis software version 8 (SAS Institute, Carey, NC).

\section{Results}

Lung function parameters in the parental strains, F1, and $\mathrm{F} 2$ progeny of the $\mathrm{B} 6$ and $\mathrm{KK}$ intercross

The increase in dynamic and airway resistance due to methacholine exposure were detected in the parental strains $\mathrm{B} 6$ and $\mathrm{KK}$, the reciprocal $\mathrm{F} 1$ progeny (KK females crossed to B6 males and B6 females crossed to KK males), and the F2 intercross progeny mice from the matings of $(\mathrm{KK} \times \mathrm{B} 6) \mathrm{F} 1$ mice. Mean values $\pm \mathrm{SEM}$ for each group and sex are reported in Table 1 for slope values and in Supplemental Table 1 for per-dose values. The absolute slope values were significantly greater in KK than B6 mice. The F1 mice were more likely to resemble the B6 parent for increase in airway resistance, suggesting that recessive genes cause the phenotypes observed in KK mice. Phenotypes of F1 mice were intermediate between the two 
Table 1 Increase in dynamic and airway resistance in response to methacholine in parental strains and F1 and F2 progeny

\begin{tabular}{|c|c|c|c|c|c|c|}
\hline \multirow[t]{2}{*}{ Phenotype } & \multirow[t]{2}{*}{ Group } & \multicolumn{2}{|l|}{ Females } & \multicolumn{2}{|l|}{ Males } & \multirow{2}{*}{$\begin{array}{l}\text { Sex differences } \\
P \text { value }\end{array}$} \\
\hline & & Mean \pm SEM & Levels & Mean \pm SEM & Levels & \\
\hline \multirow[t]{5}{*}{$R$ slope } & KK & $0.33 \pm 0.05$ & A & $0.50 \pm 0.04$ & A & $<0.01$ \\
\hline & B6 & $0.10 \pm 0.01$ & $\mathrm{C}$ & $0.21 \pm 0.03$ & $\mathrm{C}$ & $<0.01$ \\
\hline & $\mathrm{KK} \times \mathrm{B} 6 \mathrm{~F} 1$ & $0.19 \pm 0.01$ & B & $0.31 \pm 0.03$ & $\mathrm{~B}, \mathrm{C}$ & $<0.01$ \\
\hline & B6 $\times$ KKF1 & $0.15 \pm 0.01$ & $\mathrm{~B}, \mathrm{C}$ & $0.30 \pm 0.02$ & $\mathrm{~B}, \mathrm{C}$ & $<0.01$ \\
\hline & $\mathrm{KK} \times \mathrm{B} 6 \mathrm{~F} 2$ & $0.17 \pm 0.01$ & B & $0.30 \pm 0.01$ & B & $<0.001$ \\
\hline \multirow[t]{5}{*}{$R_{\mathrm{n}}$ slope } & KK & $0.38 \pm 0.03$ & A & $0.43 \pm 0.06$ & A & \\
\hline & B6 & $0.17 \pm 0.02$ & B & $0.25 \pm 0.02$ & B & \\
\hline & $\mathrm{KK} \times \mathrm{B} 6 \mathrm{~F} 1$ & $0.19 \pm 0.01$ & B & $0.33 \pm 0.04$ & A, B & $<0.001$ \\
\hline & B6 $\times$ KKF1 & $0.22 \pm 0.01$ & B & $0.32 \pm 0.02$ & A, B & $<0.01$ \\
\hline & $\mathrm{KK} \times \mathrm{B} 6 \mathrm{~F} 2$ & $0.21 \pm 0.01$ & B & $0.30 \pm 0.01$ & B & $<0.001$ \\
\hline
\end{tabular}

One-way ANOVA analysis was performed to compare lung function parameters between parental strains and progenies in female and male mice. Slope is equivalent to the increase in dynamic and airway resistance in response to consecutive doses methacholine. Levels that are not connected by the same letters are significantly different $(P<0.05)$. Statistical analyses were performed using JMP 8.0. $R$ dynamic resistance, $R_{\mathrm{n}}$ airway resistance

parents for increase in dynamic resistance. The reciprocal F1 progeny resembled each other, ruling out non-Mendelian inheritance such as imprinting and mitochondrial genes. Phenotype values in KK and B6 males are significantly higher than in KK and B6 females, respectively, for increase in dynamic but not for airway resistance.

Main and interacting effect QTLs in the F2 population

The main effect QTLs were identified first using sex as an additive covariate, then using sex as an interactive covariate, and finally using the difference between sex as additive and interactive covariates to detect sex-specific QTLs. Table 2 lists the significant and suggestive QTLs detected with sex as an additive covariate together with the QTL peaks, the $95 \%$ confidence intervals (CI), the LOD scores, and the high alleles. Three significant QTLs (one on Chr X for increase in dynamic resistance and two on Chr 2 and 3 for increases in airway resistance) were found and named according to nomenclature rules, with Lng for lung function phenotype followed by a letter designating the type of lung function $-R$ for dynamic resistance and $R_{\mathrm{n}}$ for airway resistance-followed by a number for the QTL of that class. No sex-specific main-effect QTLs were identified.

We carried out pairwise scans to detect interacting QTLs. The interacting QTLs, for which sex was used as an additive covariate, are shown in Table 3 . In particular, we found that the significant main-effect QTL on Chr X for increase in dynamic resistance interacts with QTLs on Chr 7 at $74.5 \mathrm{cM}$, Chr 15 at $53.8 \mathrm{cM}$, and Chr 17 at $17 \mathrm{cM}$. The gene encoding vitamin $\mathrm{D}$ receptor $(V d r)$ maps to the peak of the interacting Chr 15 QTL. No sex-specific interacting QTLs were identified.
Lung function testing in strains grouped according to vitamin D receptor polymorphism

The $V d r$ gene contains a SNP that is polymorphic between B6 (A allele) and KK (T allele) in exon 8 (rs16805339). This polymorphism is responsible for an amino acid change at position 276; mice that carry the A allele have methionine and those that carry the $\mathrm{T}$ allele have a lysine. Using strains, for which we previously reported airway responsiveness (Leme et al. 2010), we compared the average increase in airway resistance between strains that carry the A allele (B6-like strains: A/J, BALB/cByJ, C3H/ $\mathrm{HeJ}, \mathrm{C} 57 \mathrm{BL} / 6 \mathrm{~J}, \mathrm{FVB} / \mathrm{NJ})$ and strains that carry the $\mathrm{T}$ allele (KK-like: 129S1/SvImJ, AKR/J, BTBRT<+>tf/J, DBA/ 2J, KK/HIJ, NOD/LtJ, NZW/LacJ) at rs16805339. If both, female and male mice were analyzed together, strains carrying the KK-like allele have a significant greater increase in airway resistance compared to strains that carry the B6-like allele (Fig. 1a). The difference between $\mathrm{KK}$ - and B6-like strains is greater in females than in males (Fig. 1b); however, the difference was not significant either for females or for males.

Lung function testing of vitamin D receptor-deficient mice

Airway responsiveness was investigated previously in $V d r$ deficient mice in which lung function were decreased compared to the control mice (Wittke et al. 2004). Because the genetic background of the mice was not specified in the original paper and because airway function was detected with unrestrained plethysmography we decided to repeat those experiments. We investigated naïve, adult $V d r$-KO, $V d r$ - 
Table 2 Significant and suggestive QTLs (using sex as an additive covariate) from the intercross between the strains KK and B6

\begin{tabular}{|c|c|c|c|c|c|c|c|c|}
\hline Chr & SNP ID & Peak (cM) & $95 \% \mathrm{CI}(\mathrm{cM})$ & Trait & LOD & High allele, sex & Allele effect & Name \\
\hline 1 & rs 32707440 & 64.2 & $22.2-90.2$ & $R$ & 3.6 & KK & Dominant & \\
\hline \multirow[t]{2}{*}{2} & rs3691210 & & & $R$ & 3.0 & B6 & Intermediate & \\
\hline & & 79.9 & 73.9-103.8 & $R_{\mathrm{n}}$ & $3.8^{\mathrm{a}}$ & B6 & Intermediate & Lngrn1 \\
\hline \multirow[t]{2}{*}{3} & rs6327630 & 20.3 & $12.0-40.0$ & $R_{\mathrm{n}}$ & $3.8^{\mathrm{a}}$ & $\mathrm{KK}$ & Recessive & Lngrn2 \\
\hline & Rs3674810 & 31.5 & $8.0-42.0$ & $R$ & 2.6 & KK & Intermediate & \\
\hline 4 & rs 3705454 & 45.6 & $39.5-67.1$ & $R$ & 2.4 & KK & Recessive & \\
\hline \multirow[t]{2}{*}{5} & rs 13478240 & & & $R$ & 3.1 & KK & Dominant & \\
\hline & rs33712526 & 84.0 & $23.3-85.2$ & $R_{\mathrm{n}}$ & 3.3 & KK & Dominant & \\
\hline \multirow[t]{2}{*}{8} & rs31086651 & 60.8 & $32.8-66.0$ & $R$ & 2.8 & B6 & Dominant & \\
\hline & & & & $R_{\mathrm{n}}$ & 2.5 & HET & & \\
\hline \multirow[t]{2}{*}{10} & rs6326263 & 36.2 & $10.4-53.9$ & $R$ & 2.4 & KK & Dominant & \\
\hline & & & & $R_{\mathrm{n}}$ & 2.7 & KK & Dominant & \\
\hline 17 & rs 3702604 & 19.6 & $15.0-31.9$ & $R_{\mathrm{n}}$ & 2.4 & HET & & \\
\hline \multirow[t]{2}{*}{19} & rs 13483561 & & & $R$ & 3.7 & KK & Dominant & \\
\hline & & & & $R_{\mathrm{n}}$ & 3.1 & KK & Dominant & \\
\hline \multirow[t]{2}{*}{$\mathrm{X}$} & rs 13483765 & 32.5 & $28.5-56.5$ & $R$ & $4.8^{\mathrm{a}}$ & B6 & & Lngrl \\
\hline & rs13483921 & 54.5 & $32.0-60.5$ & $R_{\mathrm{n}}$ & 4.0 & B6 & & \\
\hline
\end{tabular}

QTL analysis was performed for each phenotype using sex as additive covariate. The strongest QTL of each chromosome (Chr) was reported with the location of its peak (Peak) and the start and the end of the $95 \%$ confidence interval $(95 \% \mathrm{CI})$. Significant $(P<0.05)$ and suggestive $(0.63<P<0.05)$ thresholds were determined by 1,000 permutation tests. Genome-wide thresholds for autosomes and the $\mathrm{X}$ chromosome are described in the text. Peak locations are depicted in centimorgans (cM)

Chr chromosome, $C I$ confidence interval, LOD logarithm of the odds, HET heterozygote, $R$ dynamic resistance, $R_{\mathrm{n}}$ airway resistance, Lng Lung a Significant QTL

Table 3 Interacting QTLs (using sex as an additive covariate) from the intercross between the strains KK and B6

\begin{tabular}{llllllr}
\hline QTL 1 & QTL 2 & Trait & Peak 1 $(\mathrm{cM})$ & Peak 2 $(\mathrm{cM})$ & LOD.full \\
\hline 7 & $\mathrm{X}$ & $R$ & 74.5 & 52.5 & 9.5 & 10.3 \\
7 & $\mathrm{X}$ & $R_{\mathrm{n}}$ & 54.5 & 50.5 & 10.1 & 5.4 \\
15 & $\mathrm{X}$ & $R$ & 53.8 & 34.5 & 5.6 & 10.6 \\
17 & $\mathrm{X}$ & $R$ & 17.0 & 56.5 & 12.5 & 5.6 \\
19 & $\mathrm{X}$ & $R_{\mathrm{n}}$ & 22.2 & 58.5 & 5.5 \\
\hline
\end{tabular}

Pairwise scan QTL analysis was performed to detect interacting QTL for each phenotype using sex as additive covariate. Interacting QTLs are reported with their chromosomes (QTL 1 and QTL 2) and peak locations (Peak1 and Peak 2) and the LOD scores for the full model (LOD.full) and the interactive model (LOD.int). Peak locations are depicted in centimorgans (cM)

$C h r$ chromosome, $L O D$ logarithm of the odds, $R$ dynamic resistance, $R_{\mathrm{n}}$ airway resistance

HET, and $V d r$-WT for airway responsiveness in response to increasing methacholine dose inhalations. Contrary to the previous investigations, we found that $V d r$-KO mice are significantly more responsive than $V d r$-HET and $V d r$-WT mice ( $P=0.014$ and $P=0.009$, respectively) (Fig. 2).

Lung function in mice maintained on diets with varying vitamin $\mathrm{D}$ concentrations

We examined male mice of the strain $\mathrm{A} / \mathrm{J}$, because this strain is more responsive to methacholine than B6 but shows the same genotype (A-allele) as B6 at the $V d r$ polymorphism (rs16805339). After weaning mice were maintained on diets that only differed in their vitamin D contents. We found that in A/J males dietary vitamin $\mathrm{D}$ had a significant effect on serum vitamin $\mathrm{D}$ concentrations $(4.5 \pm 1.9 \mathrm{ng} / \mathrm{ml}$ for deficient diet, $15.7 \pm 1.9$ for standard diet, and $53.2 \pm 1.9 \mathrm{ng} / \mathrm{ml}$ for enriched diet, respectively; $P<0.001)$. However, the dietary vitamin D concentrations did not have a significant effect on the increase in dynamic and airway resistance (Fig. 3a, b, respectively).

Serum vitamin D concentration in parental strains

Because the effects of vitamin D are not only due to the availability and functionality of the $V d r$ but also due to 

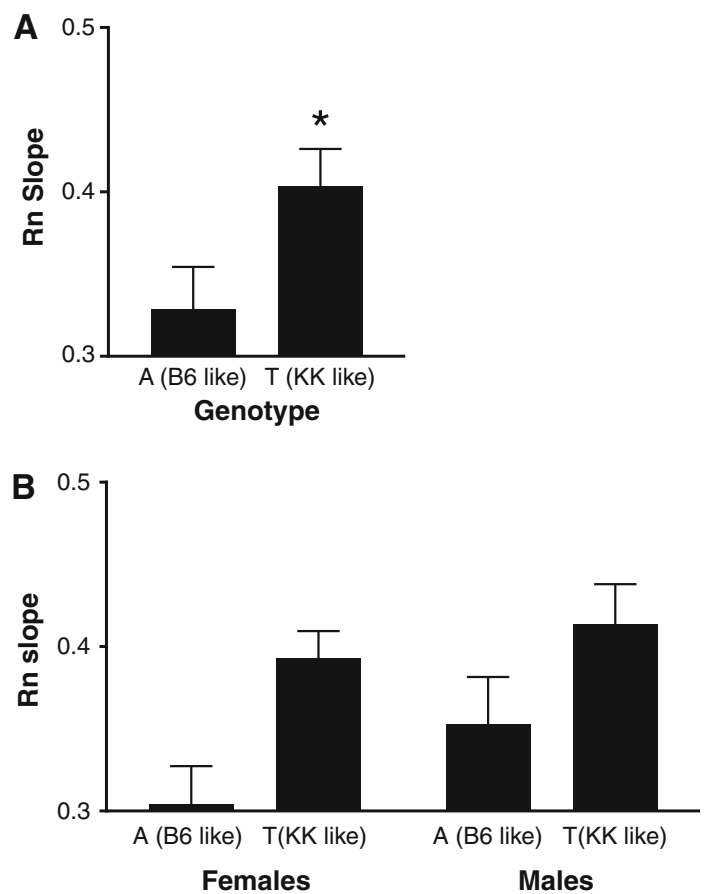

Fig. 1 Airway resistance in strains grouped by $V d r$ allele. Airway resistance is depicted as slope of the increase in airway resistance $\left(R_{\mathrm{n}}\right.$ slope) caused by consecutive doses of methacholine exposure. Female and male mice were analyzed either together (a) or separately (b). Strains were divided into a B6-like and KK-like group depending on the allele at the non-synonymous SNP (rs16805339) on exon 8 of the $V d r$. *Significantly different

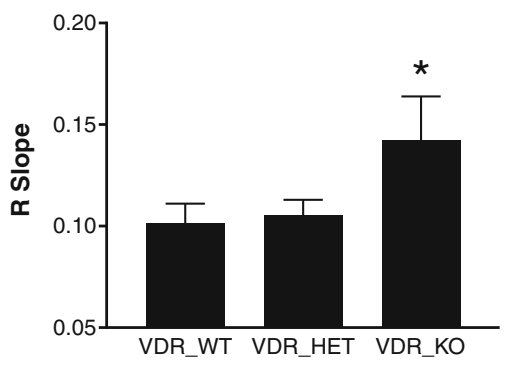

Fig. 2 Dynamic resistance in $V d r$ knockout mice. Increase in dynamic resistance ( $R$ slope) caused by consecutive doses of methacholine exposure in mice deficient in $V d r(V d r-\mathrm{KO})$ and mice carrying one $(V d r$ HET) or two copies $(V d r$-WT $=\mathrm{B} 6)$ of $V d r$. $*$ Significantly different

availability of vitamin D itself we determined the vitamin $\mathrm{D}$ concentrations in serum samples of the parental strains $\mathrm{KK}$ and B6. We found that male mice of strain B6 have significantly higher serum vitamin $\mathrm{D}$ concentrations than males of strain $\mathrm{KK}(24.6 \pm 1.6$ and $16.4 \pm 1.6 \mathrm{ng} / \mathrm{ml}$, respectively; $P=0.01$ ) (Fig. 4).

Serum vitamin D concentrations and airway resistance in a strain survey

To identify if airway resistance correlated with serum vitamin D concentrations among strains we performed a 18
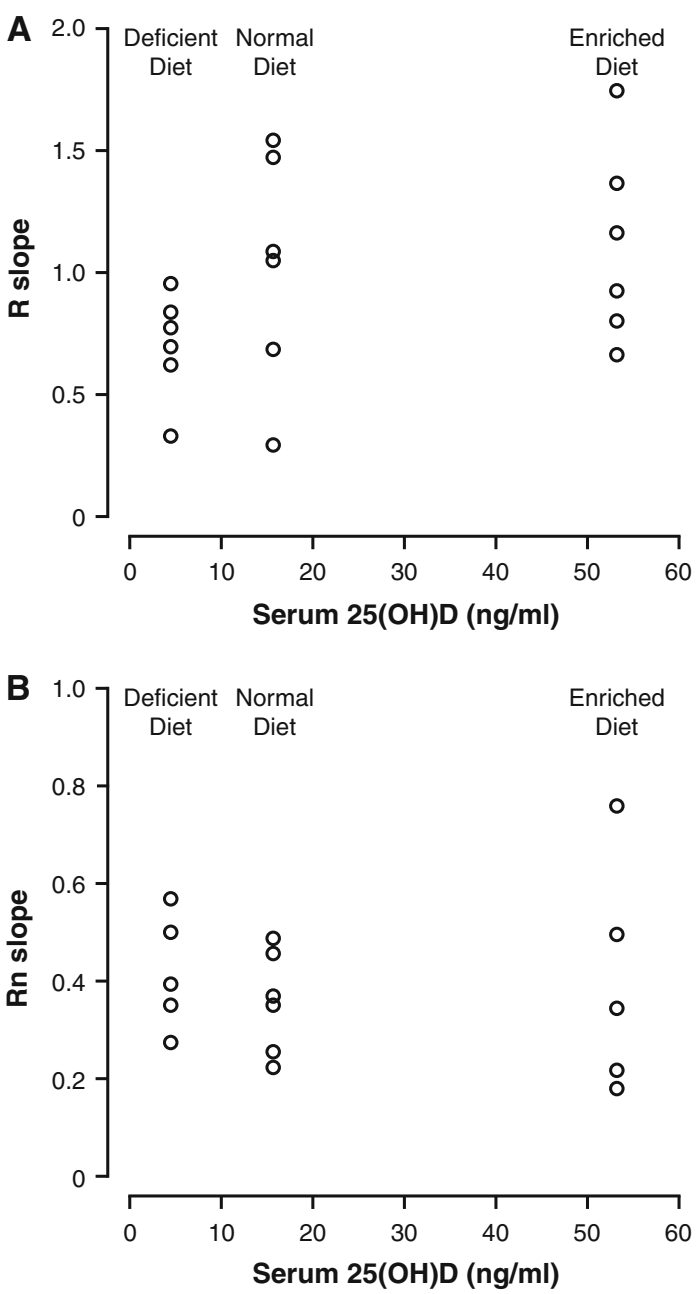

Fig. 3 Lung function in A/J mice maintained on varying dietary vitamin $\mathrm{D}$ concentrations. Increase in airway $\left(R_{\mathrm{n}}\right.$ slope, a) and dynamic resistance ( $R$ slope, $\mathbf{b}$ ) were measured in mice with differing vitamin D serum concentrations due to feeding diets with low (vitamin D deficient), standard (vitamin D standard), and high (vitamin D enriched) dietary vitamin D concentrations. *Significantly different

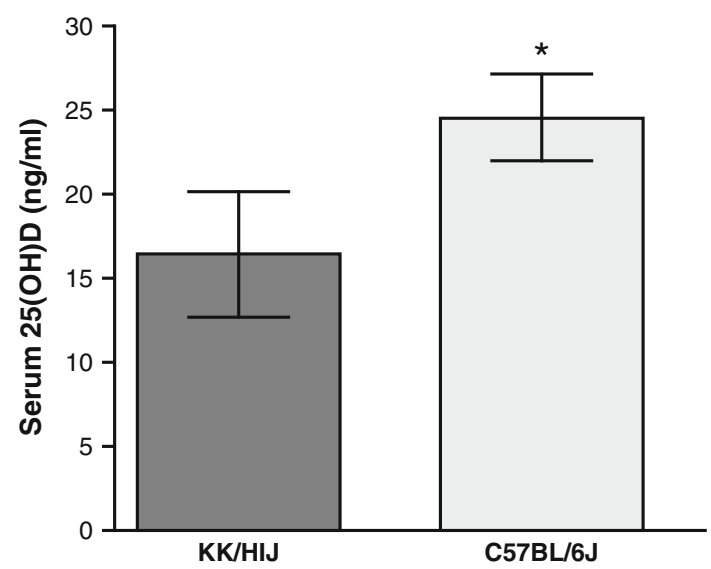

Fig. 4 Serum concentrations of $25(\mathrm{OH})$ vitamin $\mathrm{D} 3(25(\mathrm{OH}) \mathrm{D})$ in male mice of strains KK/HIJ and C57BL/6J. *Significantly different 


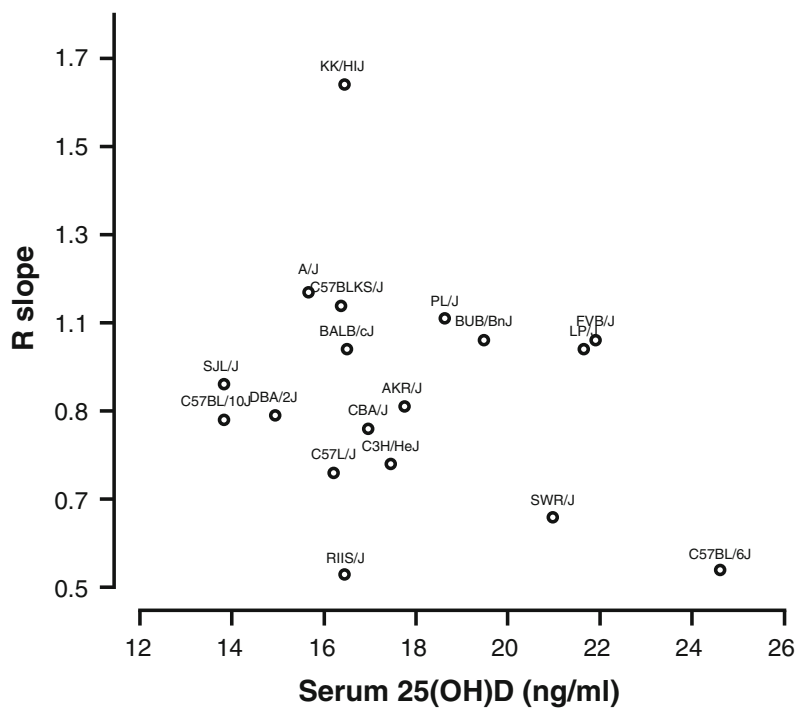

Fig. 5 Association between serum vitamin D concentration and increase in airway resistance $\left(R_{\mathrm{n}}\right.$ slope $)$ in a survey of 18 inbred strains

strain survey for serum vitamin D of a subset of strains, for which airway resistance was published recently (Leme et al. 2010). We did not find a significant correlation between airway resistance and serum vitamin D concentrations. However, often strains with high airway resistance had lower serum vitamin D concentrations (e.g., KK, A/J) and strains with low airway resistance showed higher serum vitamin D concentrations (e.g., B6, RIIIS/J, SWR/J) (Fig. 5).

\section{Discussion}

In this study we reported genetic evidence that $V d r$ is influential to dynamic and airway resistance among several strains of inbred mice. For dynamic resistance, an interacting QTL between the significant Chrs X QTL and a Chr 15 QTL was detected in the $\mathrm{F} 2$ population of the genetic cross between strains KK and B6. The peak of the Chr 15 QTL mapped to the $V d r$ locus. Several strains that differed in a $\mathrm{Cn}$ SNP allele on exon 8 of $V d r$ also differed significantly in airway resistance. Together, these findings are in agreement with several previous publications in human populations that showed linkage between $V d r$ polymorphisms and increased asthma incidence (Raby et al. 2004; Saadi et al. 2009a). Our study indicates that the effect of $V d r$ in combination with at least one other genetic variation on $\mathrm{Chr} \mathrm{X}$ contributes more than $5 \%$ to the overall phenotypic variance in dynamic resistance. The interacting variation on $\mathrm{Chr} \mathrm{X}$ needs to be further investigated in future investigations.

We observed that mice deficient in both copies of $V d r$ have a higher dynamic resistance than mice with one or two copies of the receptor. This is contrary to the previous report on airway responsiveness in $V d r$ knockout mice by Wittke et al. (2004). There were several reasons why we decided to repeat the previously reported experiments. First, the genetic background of the mice was not specified in the original paper, which indicates that it may have been mixed (e.g., embryonic stem cells made in 129 and then crossed to B6 is a typical scheme). Also, our method to measure airway function differed from Wittke et al. (2004). While latter used non-invasive, unrestrained plethysmography we used invasive forced oscillation to measure lung function, which we think is the better method to determine lung function accurately in the mouse (Berndt et al. 2011). For example, we previously showed while B6 is the least responsive strain using invasive forced oscillation, it is an intermediate responsive strain when using plethysmography. In addition, Wittke et al. (2004) investigated an allergic model of asthma while we measured naïve mice. From our observations, we conclude that the lack of $V d r$ leads to an increase in dynamic resistance. We did not observe differences in $V d r$ knockout, heterozygote, and wild-type mice for airway resistance. This was surprising to us, especially in the light of differing airway resistance among strains with differencing $V d r$ genotypes. An explanation could be the use of both male and female mice for the $V d r$ knockout experiment compared to the use of only males in the strain survey experiment. $V d r$ may be more influential to airway resistance in males than in females. This conclusion is supported by our previous report on significant gender differences for lung function in a survey of 36 inbred strains (Berndt et al. 2011).

Signaling through $V d r$ is not only determined by functionality of $V d r$, but also by the availability of its ligandvitamin D. Thus, we measured vitamin D in the serum of several strains. Interestingly, the concentration of vitamin $\mathrm{D}$ is significantly different between the parental strains of our cross. B6, which is the less responsive strain, has a significantly higher vitamin $\mathrm{D}$ serum concentration than $\mathrm{KK}$, the more responsive strain. In addition to KK and B6, we investigated 16 other strains (a total of 18 strains) and found a wide variation in serum vitamin $\mathrm{D}$. This suggests that the level of serum vitamin D may be regulated differentially among inbred strains. There was no significant association between serum vitamin D concentrations and airway resistance among all 18 strains; however, strains with high airway resistance, such as $\mathrm{KK}$ and $\mathrm{A} / \mathrm{J}$, had low serum vitamin $\mathrm{D}$ concentrations and strains with low airway resistance, such as B6 and RIIIS/J, had high levels of serum vitamin $\mathrm{D}$. The lack of significant correlation is most likely due to a more complex regulation of airway resistance than just through vitamin D. Finally, the association between serum vitamin $\mathrm{D}$ and airway resistance was performed only in males and these results may be different for 
female mice. Latter need to be investigated in a subsequent study to identify the degree of association between serum vitamin $\mathrm{D}$ and airway resistance for this gender.

Because some strains with low airway resistance had higher serum vitamin D concentration we were interested if high airway resistance could be reversed in a strain with low serum vitamin $\mathrm{D}$ by increasing the vitamin $\mathrm{D}$ concentration using a dietary regimen. For this experiment we used the strain A/J because it had the same $V d r$ genotype as B6 but a higher airway resistance when maintained under the same condition (i.e., on same diet). We observed that higher and lower dietary vitamin $\mathrm{D}$ concentrations for 7 weeks (4-11 weeks of age) lead to higher and lower serum vitamin D concentrations, respectively. However, we did not observe significant airway resistance differences between the mouse groups on different diets. A previous study showed that dietary vitamin D deficiency during pregnancy causes decreased lung growth and, thus, lung volume, which caused the change in lung function (Zosky et al. 2011). Therefore, it can be assumed that dietary vitamin D manipulation may improve lung function when administered during pregnancy but not during adulthood.

Finally, we observed significant QTLs for airway resistance on Chr 2 and 3. The Chr 2 QTL was found previously in two B6 and A/J crosses for airway responsiveness (De Sanctis et al. 1995; Ackerman et al. 2005). Using the genetic information of parental strains from overlapping QTLs genomic regions can be narrowed to possible candidates, such as the cDNA sequence BC018465, matrix metallopeptidase 9 (Mmp9), and $\mathrm{Cd} 40$ antigen $(\mathrm{Cd} 40)$. On the contrary, the Chr 3 QTL has not been reported before and, therefore, represents a novel locus that likely influences airway resistance. Toll-like receptor 2 ( $T l r 2)$, which has been associated with asthma phenotypes, is located within the Chr 3 QTL boundaries. Verification of these molecules will be necessary in future studies.

In summary, we found genetic evidence that $V d r$ in combination with at least one other genomic variation on $\mathrm{Chr} \mathrm{X}$ contributes to the phenotypic variation in dynamic resistance. We found that airways of $V d r$ knockout mice are more responsive than wild-type mice. Yet, dietary vitamin $\mathrm{D}$ supplementation during adulthood does not rescue the phenotype. Therefore, other molecules in the $V d r$ pathway and extended network [i.e., Chr $\mathrm{X}$ gene(s)] may contribute to the regulation of dynamic and airway resistance.

Acknowledgments The authors would like to thank Joanne Currer for her help in preparing the manuscript and Jesse Hammer for his assistance in preparing the graphics. This work was supported by the grant PO 083069 from the National Institutes of Health, US.

Conflict of interest None.
Open Access This article is distributed under the terms of the Creative Commons Attribution Noncommercial License which permits any noncommercial use, distribution, and reproduction in any medium, provided the original author(s) and source are credited.

\section{References}

Ackerman KG, Huang H, Grasemann H, Puma C, Singer JB, Hill AE, Lander E, Nadeau JH, Churchill GA, Drazen JM, Beier DR (2005) Interacting genetic loci cause airway hyperresponsiveness. Physiol Genomics 21(1):105-111

Berndt A, Leme AS, Williams LK, Von Smith R, Savage HS, Stearns TM, Tsaih SW, Shapiro SD, Peters LL, Paigen B, Svenson KL (2011) Comparison of unrestrained plethysmography and forced oscillation for identifying genetic variability of airway responsiveness in inbred mice. Physiol Genomics 43(1):1-11

Cox A, Ackert-Bicknell CL, Dumont BL, Ding Y, Bell JT, Brockmann GA, Wergedal JE, Bult C, Paigen B, Flint J, Tsaih SW, Churchill GA, Broman KW (2009) A new standard genetic map for the laboratory mouse. Genetics 182(4):1335-1344

De Sanctis GT, Merchant M, Beier DR, Dredge RD, Grobholz JK, Martin TR, Lander ES, Drazen JM (1995) Quantitative locus analysis of airway hyperresponsiveness in $\mathrm{A} / \mathrm{J}$ and $\mathrm{C} 57 \mathrm{BL} / 6 \mathrm{~J}$ mice. Nat Genet 11(2):150-154

Devereux G, Litonjua AA, Turner SW, Craig LC, McNeill G, Martindale S, Helms PJ, Seaton A, Weiss ST (2007) Maternal vitamin $\mathrm{D}$ intake during pregnancy and early childhood wheezing. Am J Clin Nutr 85(3):853-859

Leme AS, Berndt A, Williams LK, Tsaih SW, Szatkiewicz JP, Verdugo R, Paigen B, Shapiro SD (2010) A survey of airway responsiveness in 36 inbred mouse strains facilitates gene mapping studies and identification of quantitative trait loci. Mol Genet Genomics 283(4):317-326

Masoli M, Fabian D, Holt S, Beasley R (2004) The global burden of asthma: executive summary of the GINA Dissemination Committee report. Allergy 59(5):469-478

Mu JL, Naggert JK, Svenson KL, Collin GB, Kim JH, McFarland C, Nishina PM, Levine DM, Williams KJ, Paigen B (1999) Quantitative trait loci analysis for the differences in susceptibility to atherosclerosis and diabetes between inbred mouse strains C57BL/6J and C57BLKS/J. J Lipid Res 40(7):1328-1335

Peters LL, Robledo RF, Bult CJ, Churchill GA, Paigen BJ, Svenson KL (2007) The mouse as a model for human biology: a resource guide for complex trait analysis. Nat Rev Genet 8(1):58-69

Raby BA, Lazarus R, Silverman EK, Lake S, Lange C, Wjst M, Weiss ST (2004) Association of vitamin D receptor gene polymorphisms with childhood and adult asthma. Am J Respir Crit Care Med 170(10):1057-1065

Saadi A, Gao G, Li H, Wei C, Gong Y, Liu Q (2009a) Association study between vitamin $\mathrm{D}$ receptor gene polymorphisms and asthma in the Chinese Han population: a case-control study. BMC Med Genet 10:71

Saadi HF, Dawodu A, Afandi B, Zayed R, Benedict S, Nagelkerke N, Hollis BW (2009b) Effect of combined maternal and infant vitamin D supplementation on vitamin D status of exclusively breastfed infants. Matern Child Nutr 5(1):25-32

Sheehan S, Tsaih SW, King BL, Stanton C, Churchill GA, Paigen B, DiPetrillo K (2007) Genetic analysis of albuminuria in a cross between C57BL/6J and DBA/2J mice. Am J Physiol Renal Physiol 293(5):F1649-F1656

Solberg LC, Baum AE, Ahmadiyeh N, Shimomura K, Li R, Turek FW, Churchill GA, Takahashi JS, Redei EE (2004) Sex- and 
lineage-specific inheritance of depression-like behavior in the rat. Mamm Genome 15(8):648-662

Stevenson CS, Birrell MA (2011) Moving towards a new generation of animal models for asthma and COPD with improved clinical relevance. Pharmacol Ther 130(2):93-105

Stylianou IM, Paigen B, Singh J, Schwartz DA (2007) Comparative genomics of asthma. In: Dirkje S, Postma STW (eds) Genetics of asthma and chronic obstructive pulmonary disease (Lung biology in health and disease). Informa Healthcare USA. Inc, New York, pp 159-177
Su Z, Ishimori N, Chen Y, Leiter EH, Churchill GA, Paigen B, Stylianou IM (2009) Four additional mouse crosses improve the lipid QTL landscape and identify Lipg as a QTL gene. J Lipid Res 50(10):2083-2094

Wittke A, Weaver V, Mahon BD, August A, Cantorna MT (2004) Vitamin D receptor-deficient mice fail to develop experimental allergic asthma. J Immunol 173(5):3432-3436

Zosky GR, Berry LJ, Elliot JG, James AL, Gorman S, Hart PH (2011) Vitamin D deficiency causes deficits in lung function and alters lung structure. Am J Respir Crit Care Med 183(10):1336-1343 